\title{
REDESIGN LOGO CAFE DAN RESTO RUMAH BAKO PAYAKUMBUH
}

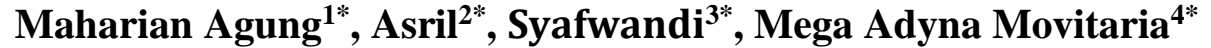 \\ Penciptaan dan Pengkajian Seni Program Pascasarjana ${ }^{1,2 *}$ \\ Institut Seni Indonesia Padangpanjang \\ Jl. Bahder Johan, Guguak Malintang, Padangpanjang, Kota Padangpanjang, Kode Pos 27126 \\ Program Studi Desain Komunikasi Visual Jurusan Seni Rupa Fakultas Bahasa dan Seni ${ }^{3 *}$ \\ Universitas Negeri Padang \\ Jl. Prof. Dr. Hamka, Air Tawar Padang, Kel. Air Tawar Barat, Kec. Padang Utara, Kota Padang, Kode \\ Pos 25132 \\ Fakultas Tarbiyah dan Ilmu Keguruan ${ }^{4 *}$ \\ Institut Agama Islam Sumatera Barat \\ Jl. Wolter Monginsidi, Kp. Gadang, Kec. Pariaman Timur, Kota Pariaman, Kode Pos 25516 \\ Sumatera Barat. Indonesia \\ Email:maharianagung27@gmail.com, asrilmuchtar2017@gmail.com, onedaykuroishi@gmail.com, \\ megaadyna@iaisumbar.ac.id
}

\begin{abstract}
Abstrak
Artikel ini bertujuan untuk mengungkap proses perancangan (Cafe ) logo Cafe dan Resto Rumah Bako. Redesign ini dilakukan berdasarkan berbagai kelemahan yang ditemukan pada logo Resto Rumah Bako yang terdahlu. Redesign ini didekati dengan teori, logo, estetika, warna, dan gaya seni. Metode yang digunakan dalam penelitian ini adalah metode 4D yaitu: define (definisi), design (perancangan), develop (pengembangan), dan dessiminate (penyebaran). Logo baru dari Cafe dan Resto Rumah Bako Payakumbuh adalah hasil dari pengolahan bentuk lingkaran dengan font dan gambar. Gambar yang diambil adalah sebagai ikon produk yaitu kuliner. Pemilihan posisi dan letak sangat diperhitungkan. Melalui media utama yaitu logo dan media pendukung seperti baju kaos, tottebag, gantungan kunci, stiker, $\mathrm{x}$-banner, dan spanduk yang bertujuan sebagai media promosi.
\end{abstract}

Kata Kunci: redesign, logo, café, resto.

\begin{abstract}
This article aims to reveal the process of designing (redesigning) the logo of the Rumah Bako Cafe and Resto. This redesign was carried out based on various weaknesses found in the previous Rumah Bako Resto logo. This redesign was approached with theory, logo, aesthetics, color, and art style. The method used in this study is the 4D method, namely: define (definition), design (design), develop (development), and dessiminate (spread). The new logo of Rumah Bako Payakumbuh Cafe and Resto is the result of processing circle shapes with fonts and images. The picture taken is as a product icon, namely culinary. The choice of position and location is very taken into account. Through the main media, namely logos and supporting media such as $t$-shirts, totte bags, key chains, stickers, $x$-banners, and banners that aim as promotional media.
\end{abstract}

Keywords: redesign, logo, café, resto.

\section{PENDAHULUAN}

Suatu informasi bisa diterima dengan baik oleh seseorang jika instrumen penyampaiannya yaitu instrumen yang sudah dikenal oleh masyarakat luas. Pemasaran, adalah suatu daya tarik tempat yang dikemukakan supaya dapat memperkenalkan identitas Cafe serta meningkatkan kualitasnya. Beberapa bentuk pemasaran yang ada pada sekarang sudah dikenal dengan logo. Audience sering menggunakannya tetapi tidak mengetahui logo yang berkembang di sekitarnya. Mulai dari mug yang dipakai, piring, baju, aksesoris dan lain-lain. Logo bertujuan untuk memberitu masyarakat luas mengenai identitas serta keunikan
Cafe dan juga membantu audiens dalam mengenali produk yang diinginkannya. Logo tidak hanya sebagai tanda maupun merek barang tetapi logo menjadi senjata bisnis. Dan juga logo sudah menjadi daya tarik untuk meningkatkan ketertarikan konsumen pada produk yang diciptakannya.

Logo Cafe harus mampu menjelaskan ciri Cafe, sehingga mampu mempengaruhi ketertarikan konsumen pada waktu yang singkat. Logo yang tidak dapat menyajikan unsur tersebut, perlu dilakukan perancangan ulang. Perubahan yang terjadi pada logo dapat memperbaiki dalam bidang perusahaan supaya dapat meningkatkan daya tarik konsumen. Logo, 
Gorga : Jurnal Seni Rupa

Volume 10 Nomor 02 Juli-Desember 2021

p-ISSN: 2301-5942 | e-ISSN: 2580-2380

maskot, slogan, label, slserta etiket adalah bagian dari corporate identity. Maka dari itu logo adalah corporate identity yang sudah dikenal luas oleh masyarakat. Tulisan ini membahas redesign logo corporate identity "Cafe Rumah Bako" di Payakumbuh.

Redesign logo Cafe dan Resto Rumah Bako Payakumbuh dibuat untuk menarik konsumen ataupun pengunjung baru agar datang ke Cafe dan Resto Rumah Bako Payakumbuh tersebut, sehingga omset Cafe dan Resto tersebut bertambah, sekaligus logo Cafe dan Resto Rumah Bako Payakumbuh berfungsi sebagaimana fungsi seharusnya logo digunakan. Logo lama belum membuat orang lain tahu apa sebenarnya Cafe dan Resto Rumah Bako Payakumbuh tersebut, karena belum adanya identitas Cafe ataupun Resto pada logo, sehingga orang yang melihat mengira bahwa Cafe dan Resto Rumah Bako Payakumbuh hanyalah sebatas nama atau kata-kata Minang yang dibuat.

Beberapa orang yang diwawancarai tentang logo Cafe dan Resto Rumah Bako Payakumbuh tersebut, jawaban mereka sama, yaitu "tidak tau bahwa rumah bako adalah Cafe dan Resto ran." Cafe dan Resto Rumah Bako Payakumbuh yang terletak di puncak bukit di Payakumbuh yang cukup jauh dari pusat kota membuat kurangnya minat pengunjung datang karena tidak ada penunjuk jalan menuju ke sana.

Setelah diidentifikasi, terdapat beberapa masalah, yaitu: logo Cafe dan Resto Rumah Bako Payakumbuh yang lama kurang efektif dan informatif, sehingga belum optimal memberikan makna logo bagi Cafe dan Resto Rumah Bako Payakumbuh.

Berdasarkan identifikasi masalah itu pendesain membuat redesign logo melalui metode analisis data dan pengumpulan data supaya redesign logo yang akan dibuat berfungsi dengan baik dan tercapai seperti keinginan owner. Redesign logo Cafe dan Resto Rumah Bako Payakumbuh yang sesuai dengan konteks desain dan konteks identitas Cafe dan Resto Rumah Bako Payakumbuh. Redesign dimaksudkan untuk memudahkan dan menjadi daya tarik bagi pengunjung, sehingga Cafe tersebut semakin bertambah pengunjungnya baik itu dari sekitar Kota Payakumbuh maupun dari luar Kota Payakumbuh. Lokasi Cafe dan Resto Rumah Bako Payakumbuh bisa jadi lebih menarik, karena tempatnya indah, pengunjung dan melihat alam Payakumbuh dari Cafe dan Resto Rumah Bako Payakumbuh, sehingga dapat menenangkan pikiran. Jika orang yang melihat logo tersebut, mereka mengetahui kalau Cafe dan Resto Rumah Bako
Payakumbuh adalah sebuah Cafe dan Resto yang menyuguhkan makanan tradisional dan moderen.

\section{KAJIAN TEORI}

Redesain diadopsi dari bahasa Inggris redesain, yaitu re dan design. Penggunaan kata re mengacu pada pengulangan atau melakukan kembali, sehinggga redesign memiliki arti sebagai desain ulang. redesign yaitu suatu perencanaan serta perancangan yang dilakukan agar mengalami perubahan dalam segi bentuk fungsi pada benda, bangunan maupun barangbarang yang dapat meningkatkan kualitasnya dari yang sebelumnya.

Menurut Van Der Vorst \& Beulens (2002), redesign yaitu perencanaan yang dilakukan agar mengalami perubahan dalam bentuk serta fungsi pada, bangunan, maupun syistemyang bertujuan untuk meningkatkan kualitas serta manfaatnya dari yang sebelumnya.

Menurut Said (2019), Logo atau tanda gambar (picture mark) yaitu itu identitas yang digunakan dalam mengidentifikasi produk serta keunikan pada perusahaan maupun lembaga organisasi. Logo type (word mark) yaitu produk yang terlihat dalam bentuk tulisan yang bertujuan untuk menjelaskan keunikan secara menyeluruh (Luffarelli, et al., 2019).

Dalam prinsipnya logo yaitu lambang yang mewakili produk yang dihasilkan oleh perusahaan (Arredondo et al., 2009). bentuk pada suatu produk perlu mempertimbangkan, seperti warna, garis, tekstur, ruang dan typografi pada cafe dan resto.

Menurut Jia, et al., (2014), cafe yaitu usaha dalam bentuk makanan yang yang diolah secara menyeluruh dapat dihidangkan kepada konsumen yang diberi layanan pada keadaan non formal yang tidak didasarkan pada aturan yang ditentukan. Macammacam makanan serta harganya lebih murah dikarenakan Iya bekerja selama 24 jam, maka dari itu cafe akan tetap buka ketika restoran-restoran lainnya tutup.

Keadaan seperti itu dapat menjadi peluang bagi masyarakat yang menyenangi bisnis cafe. Mereka berfikiran tentang selama orang-orang tidak mengalami keberatan dengan harga yang mahal serta menginginkan kan bentuk dan kenyamanan maka bisnis cafe dapat berkembang.

Tidak hanya menu serta ruangannya, cafe perlu di memperhatikan strategi pemasaran. Dikota-kota besar pemasaran harus dikuasai dikeramatkan dapat meningkatkan daya jual beli suatu produk yang 
Gorga : Jurnal Seni Rupa

Volume 10 Nomor 02 Juli-Desember 2021

p-ISSN: 2301-5942 | e-ISSN: 2580-2380

dihasilkan. Tak hanya promo di hari besar tetapi cafe harus membuat suatu pertunjukan serta paket-paket khusus. Tak hanya itu penyedi sering memberikan menu secara gratis kepad konsumen bahkan penyedia menyewa Event Organizer yang dijadikan sebagai daya tarik konsumen terhadap produknya.

Menurut Lee et al., (2016) yang menyatakan restoran memiliki maksud yakni onsite food service artinya suatu tempat yang memperjualbelikan makanan atau minuman untuk mendukung aktivitas yang termasuk non-profit, sedangkan commercial food service artinya suatu tempat yang memperjualbelikan makanan untuk mencari keuntungan.

Menurut Putri \& Hartati, (2021) Adapun masalah keindahan yaitu suatu gagasan tentang ketertarikan pada suatu produk yang di buat sehingga konsumen merasa puas dalam menggunakannya. Ketertarikan pada suatu produk harus mampu memuaskan konsumen. Unsur keindahan harus diperhatikan dalam membuatnya.

\section{Unsur Bentuk}

Unsur keindahan pertama yaitu unsur bentuk. Bentuk "shape" dapat berdampak bagi produk, bentuknya terdiri dari dua dimensi maupun tiga dimensi (Mubarat \& Ilhaq, 2021). Bentuk dua dimensi tidak mempunyai volume, kedalaman serta ruang. Seperti patung, pakaian, tas. unsur bentuk mampu meningkatkan nilai keindahan pada suatu produk yang dihasilkan sehingga dapat meningkatkan daya tarik pada konsumen (Fadilah et al., 2021).

\section{Unsur Warna}

Estetik yaitu suatu keindahan yang terdapat pada suatu produk. Menurut Atika, (2019) Warna warna dapat berdampak pada suatu produkproduk dibuat dengan menggunakan perpaduan warna yang menarik sehingga dapat meningkatkan daya tarik pada suatu produk.

\section{Unsur Tema}

Unsur tema yakni konsep maupun ide serta gagasan yang diungkapkan oleh membuat karya seni yang bertujuan untuk mempengaruhi konsumen (Arbi et al., 2019). Tema pada suatu karya dapat dipengaruhi oleh letak geografis, adat istiadat serta budaya.

\section{Unsur Motif Hias}

Motif hias yakni gambaran maupun rangkaian yang dapat dijadikan sebagai hiasan pada suatu produk untuk meningkatkan keindahan pada produk yang dibuat. (Anggakarti \& Benyamin, 2021). Tujuan dari motif hias adalah meningkatkan nilai keindahan pada objek atau produk sehingga dapat mempengaruhi konsumen.

\section{Warna}

Warna merupakan suatu spektrum yang ditemukan pada cahaya sempurna (berwarna putih) (Munawaroh, 2018). Identitas pada warna dapat diketahui dari panjang gelombang cahaya. Seperti warna biru yang mempunyai panjang gelombang 460 nanometer. Panjang gelombang warna dapat ditangkap oleh indra manusia yaitu 380-780 nanometer pada peralatan optis warna dapat diartikan perpaduan otaka pada tiga warna primer cahaya: merah, hijau, biru yang dipadukan pada tekstur yang sudah ditentukan (Susilawati et al., 2020). Seperti perpaduan $100 \%$ merah, $100 \%$ hijau, dan $100 \%$ biru akan menghasilkan interpretasi warna magenta.

Menurut Mulyawartini, (2019) warna pada seni rupa yaitu pantulan cahaya yang terjadi akibat pigmen pada permukaan benda. Seperti perpaduan magenta dengan cyan yang disinari cahaya putih sempurna dapat menghasilkan warna yang persis dengan warna merah.

Setiap warna dapat memberikan kesan yang menarik bagi pengamat serta dapat meningkatkan daya tarik pada suatu produk yang dihasilkan (Sakriyani, 2018). Seperti warna putih dapat memberikan kesan suci serta dingin didaerah Barat dikarenakan berasumsi salju. Dan di daerah Timur warna putih memiliki kesan kematian dikarenakan masyarakat berasumsi pada kain kafan (meskipun secara teoretis sebenarnya putih bukanlah warna). Pada artian warna, warna hitam tidak termasuk kedalam gelombang warna. Sementara warna putih dianggap sebagai perwakilan dari semua jenis gelombang warna. Secara ilmiah hitam dan putih bukanlah warna tetapi dapat dimasukkan ke dalam bentuk pigmen.

Perkembangan bentuk yang modern dapat menghasilkan produk yang menonton, pabrikasi, sejenis hingga dapat menimbulkan kebosanan pada beberapa konsumen. sehingga membuat beberapa masyarakat memanfaatkan barang-barang yang bersifat klasik dan memiliki nilai seni yang tinggi. Salah satunya gaya yang berkembang yaitu vintage.

Menurut Wagner et al., (2018) pada kamus Oxford, vintage yang artinya old and of very high quality. Vintage yakni barang anti dapat dilihat dari usia maupun dari bentuk yang dibuat dengan semenarik mungkin. Vintage mengingatkan sesuatu pada zaman dahulu tapi tidak membuang unsur modern yang mempengaruhinya. 
Vintage yaitu produk-produk yang diolah pada masa sekarang tetapi banyak memiliki bentuk yang klasik serta menarik yang yang mampu mengingatkan pada tahun 1920 sampai 1970an. Suatu objek yang berbentuk barang-barang biasanya mempunyai nilai serta bentuk yang bermutu pada masanya. Kata vintage ini di Eropa pertamanya dimanfaatkan dalam memanen anggur, sehingga pada saat sekarang yang masih dimanfaatkan dalam pengelolaan anggur menjadi minuman wine. Layaknya wine, makin tua harganya makin mahal. Vintage dimanfaatkan dalam menjelaskan suatu yang lama atau kuno tetapi klasik serta mempunyai nilai yang tinggi. Barang-barangnya seperti pakaian, furniture, perhiasan, sepeda, sepeda motor serta mobil.

\section{METODE PENELITIAN}

Pada penciptaan ini, perancang menggunakan metode 4D dalam mengembangkan media Motion Graphic yang digarap. Metodenya yakni Define (Definisi), Design (Perancangan), Develop (Pengembangan), dan Dessiminate (Penyebaran).

Tahapan defenisi ini adalah awal mendeskripsikan mengenai masalah, ide, serta konsep garapan perancangan yang akan diolah dalam melakukan penciptaan karya.

Setelah menyelesaikan penjabaran dan merincikan semua permasalahan yang akan diangkat menjadi sebua karya pada tahap pendefinisian, maka perancang selanjutnya melakukan perancangan. Hasil dari peranangan redesign logo yang sudah digarap akan dilakukan evaluasi karya melalui analisa SWOT dan memperlihatkan kepada beberapa responden terkait dan menilai kekurangan yang ada pada desain tersebut dan menjadi acuan perancang dalam mengkoreksi karya hingga mengubahnya dari kekurangan yang sudah dilakukan hingga menghasilkan final desain yang sesuai dengan konsep yang sudah ditentukan diawal dan mencapai tujuan karya.

Setelah melakukan uji coba dan revisi pada tahap pengembangan sehingga mendapatkan hasil final design, perancang melakukan tahapan disseminate yang merupakan taapan penyebarluasan karya kepada kalayak umum, perancang akan menyebarluaskan karya redesign logo yang telah sempurna dan sesuai konsep yang dibuat melalui pengunjung yang telah berkunjung ke Cafe tersebut dan memberikan bingkisan yang akan menjadi media promosi secara tidak langsung kepada pengunjung.

\section{HASIL DAN PEMBAHASAN}

\section{Hasil}

Cafe dan Resto Rumah Bako Payakumbuh merupakan salah satu tempat wisata kuliner atau Cafe yang ada di atas bukit Payakumbuh yang sangat recommended untuk tempat hangout bersama orang-orang tersayang. Dengan panorama keindahan alam Payakumbuh yang bisa dilihat dari Cafe tersebut. Cafe dan Resto Rumah Bako Payakumbuh berdiri di Nagari Taeh Bukik Kecamatan Payakumbuah tepatnya di Jorong Talago.

Cafe dan Resto Rumah Bako Payakumbuh berdiri pada tanggal 8 juni 2012, dalam pendirian Cafe tersebut di hadiri oleh Bupati Kabupaten Lima Puluh Kota Dr, Alis Marajo juga di hadiri anggota DPRD Lima Puluh Kota, niniak mamak, tokoh masyarakat, kepala SKDP dan lapisan pemuda, dan masyarakat Taeh Bukik.

Cafe dan Resto Rumah Bako Payakumbuh Payakumbuh memiliki tempat yang nyaman dan menyenangkan, karena Cafe dan Resto Rumah Bako Payakumbuh di buat dua ruangan outdoor dan indoor. Menurut Wangarry \& Saidi, (2018) Ruang indoor biasanya digunakan untuk mereka yang ingin melihat penampilan band yang biasanya selalu didatangkan baik untuk acara tamu maupun hiburan malam minggu. Jaya, (2018) menyatakan, di ruang outdoor digunakan untuk pengunjung yang ingin bersantai bersama keluarga maupun pasangan untuk melihat keindahan Payakumbuh dari atas bukit tersebut.

Jenis makanan yang ditawarkan tidak hanya makanan khas Minangkabau seperti rendang, lele goreng, gulai ikan dan lain-lain tetapi juga ada makanan seperti mieso, soto, pical ayam dan makanan lainnya, minumannya juga beraneka ragam. Cita rasa makanannya yang disajikan cukup enak dan unik di mana selain sambal cabai merah dan hijau turut dihidangkan pula bumbu kacang, namun berbeda dengan bumbu kacang yang diperuntukkan untuk sate maupun pecel. Teksturnya lebih encer dari sambal pecel, tetapi sedikit lebih pedas dari bumbu kacang untuk sate. Paduan rasanya unik dan cocok saat dipadukan dengan ayam bakar dan sambal merah atau hijau. Pengunjung bisa merasakan kenikmatan dari makanan ataupun minumannya juga mendapatkan kenyamanan dan keindahan alam Payakumbuh.

Langkah pertama dalam membuat logo yaitu menemukan informasi tentang barang. Barang yaitu sesuatu yang dapat dijadikan sebagai objek. Seperti logo ini yaitu logo grup maupun logo anak perusahaan. Dalam tahap perubahan dikumpulkan informasi mengenai maksud terjadinya perubahan, mengganti maupun pergeseran maksud logo sebelumnya serta yang dijadikan makna yang ingin ditampilkan. 


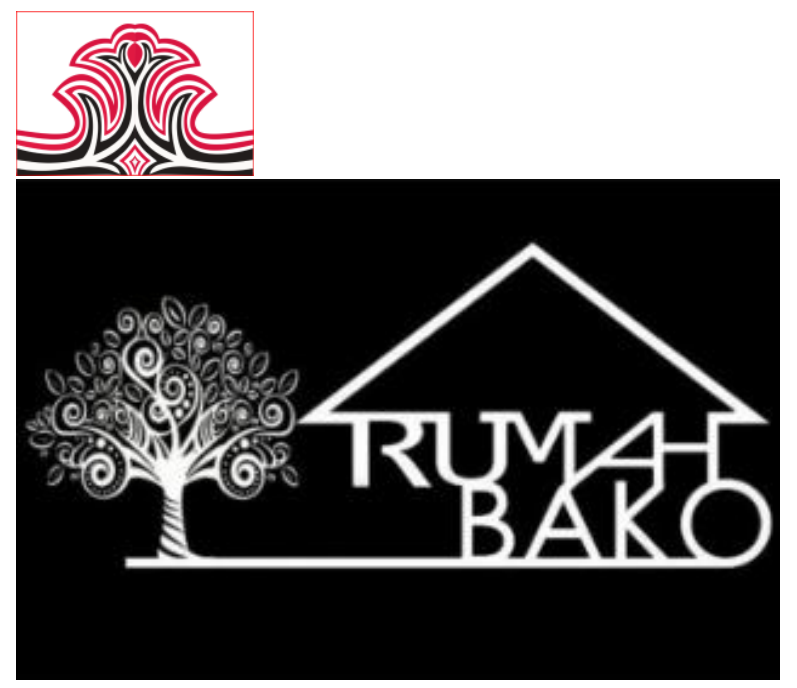

Gambar 1. Logo Lama Cafe dan Resto Rumah Bako Payakumbuh

Gambar di atas merupakan logo awal dari Cafe dan Resto Rumah Bako Payakumbuh yang menjadikan identitas merek dagang Cafe dan Resto bermutu serta dapat menjaga produk agar tetap menarik.

\section{1). Warna}

\section{(1). Hitam}

Hitam digunakan sebagai warna utama, menggambarkan kesan tenang dan elegan.

\section{(2). Putih}

Putih dipilih karena melambangkan kesederhanaan dan kesempurnaan. Hitam putih yang dimanfaatkan sebagai pelengkap dalam pembuatan logo. Dalam logo Hitam putih yang dimanfaatkan dalam bidang di bagian atas dan bawah logo. Motif polka artinya menggambarkan pattern kain, yang mewakili pakaian.

\section{a. Basic shape}

Saung adalah sesuatu yang digunakan karena Cafe dan Resto Rumah Bako Payakumbuh adalah tempat yang berbentuk rumah.

\section{b. Typography}

Jenis font yg digunakan dari logo lama terlalu tegas yang belum masuk kepada identitas suatu tempat makan dan Cafe, penanda atau tulisan Cafe dan Resto di logo yang lama belum ada sehingga menjadi kekurangan untuk org yg melihat logo lama.

\section{c. Positioning}

Logo diposisikan di media neon box di depan perkarangan sebelum masuk Cafe untuk menandakan bahwa telah sampai di Cafe rumah bako tersebut.

Tujuan redesign logo Cafe dan Resto Rumah Bako Payakumbuh sesuai dalam konteks desain dan konteks identitas Cafe dan Resto Rumah Bako Payakumbuh, sehingga jika orang yang melihat logo tersebut mengetahui kalau Cafe dan Resto Rumah Bako Payakumbuh adalah sebuah Cafe dan Resto yang menyuguhkan makanan tradisional dan moderen,
Gorga : Jurnal Seni Rupa

Volume 10 Nomor 02 Juli-Desember 2021

p-ISSN: 2301-5942 | e-ISSN: 2580-2380

tempatnya yang juga indah untk menenangkan pikiran dan melihat alam Payakumbuh dari Cafe dan Resto Rumah Bako Payakumbuh tersebut.

\section{Pembahasan}

1). Analisis $S W O T$

(1). Strength (Keunggulan)

Logo lama mempunyai kualitas warna yang cocok dengan bentuk Cafe dan Resto Rumah Bako Payakumbuh. Logonya diberi nama Rumah Bako yang subtitle-nya yang tepat. Sub title cocok jika diletakkan di bawah logo rumah, pemanfaatannya kurang menarik dari dari pada logo tetapi tetap dapat menarik.

\section{(2). Weakness (Kelemahan)}

Jenis logo terlalu menarik. Harus dibuat berdasarkan Citra yang diinginkan. Basic shape rumit, serta terlihat kuat. Kurang sesuai untuk diterapkan dalam Citra logo yang diinginkan pada pasar kuliner.

\section{(3). Opportunity (Peluang)}

Namanya yang dikenal Rumah Bako dalam logo, biarpun logonya mengalami perubahan tetapi tetap disenangi dan mudah dikenali. Resto ini telah mempunyai pengagum tersendiri, ini adalah suatu peluang yang baik meskipun logonyamengalami perubahan tetapi penyebarannya tidak susah.

\section{(4). Threat (Ancaman)}

Tidak dikenali bagi masyarakat saat perubahan logo yang tidak diketahuinya. Perubahan logo mempengaruhi daya tarik produk. Bentuk dalam aplikasi yang baru dapat disukai maupun tidak disukai.

\section{a. Konsep Logo Baru}

Kerja redisain adalah memperbaiki desain logo setelah diketahui kekurangannya. Hal ini akan berpengaruh terjadinya perubahan warna dan basic shape dalam bentuk yang diinginkan. Berbentuk kuat dan tenang berdasarkan warna hitam yang dominan, warna kuning berarti kebahagiaan, logo yang menarik dapat meningkatkan daya tariknya. 


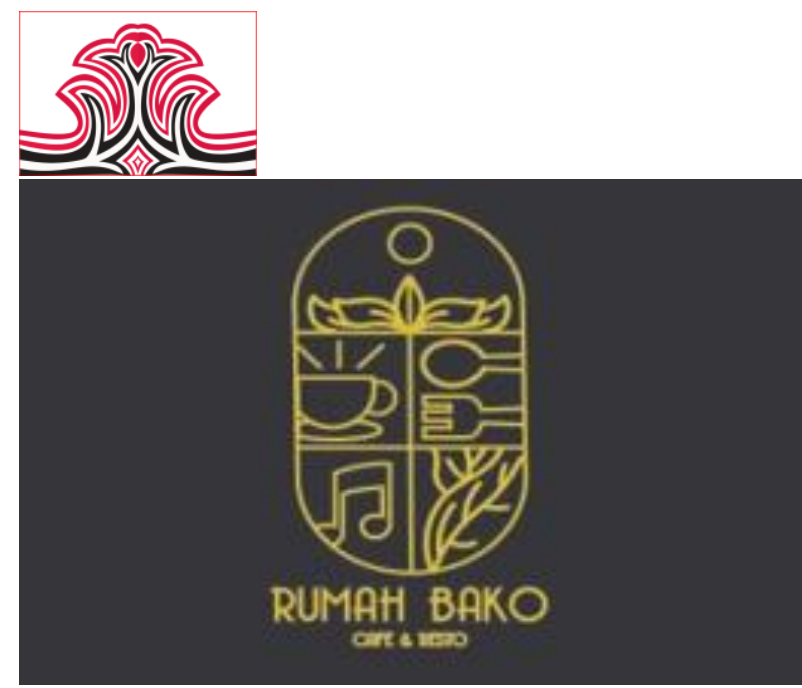

Gambar 2. Logo baru Cafe dan Resto Rumah Bako Payakumbuh

Pada logonya dapat dilihat berdasarkan bentuknya yang dikelompokkan dalam bentuk picture Mark serta letter Mark. Komponen gambar serta tulisannya berpisah pisa tetapi saling berhubungan pada lambang serta terdapat pada lingkaran yang ditentukan. Tulisan pada logo memiliki fungsi dalam menjelaskan maksud gambar, nama pada logo serta tagline dapat mencegah dalam menjelaskan maksud gambar yang menyebar dapat masuk ke tempat yang tidak ditentukan. Hingga maksudnya bisa diketahui dengan jelas tanpa mendugaduga.

Logo baru dari Cafe dan Resto Rumah Bako Payakumbuh yaitu rumah yang berbentuk lingkaran dengan ukuran serta gambar yang diinginkan. gambar yang diinginkan yaitu dijadikan sebagai lambang pada produk kuliner. Penentuan posisi serta letak rumah perlu dipertimbangkan.

Matahari menandakan kehangat dari Cafe rumah bako, gonjong rumah adat yang dibuat seperti daun menandakan letak Cafe tersebut di payakumbuh yang kuat adat minangnya, cangkir dan garis tegas itu menandakan di Cafe tersebut bisa untuk berbicara santai sambil minum dan makan, simbol garpu dan sendok adalah tempat makan atau Resto, icon musik yang menandakan di Cafe tersebut melakukan band atau musik untuk menghibur pengunjung dan bisa juga pengunjung untuk bernyanyi, sedangkan simbol daun menandakan banyaknya pepohonan dan tempat yang asri sekitaran Cafe tersebut.

\section{KESIMPULAN DAN SARAN}

\section{Kesimpulan}

Logo baru dari Cafe dan Resto Rumah Bako Payakumbuh yakni rumah yang berbentuk lingkaran dengan ukuran serta gambar yang diinginkan. Gambar yang digunakan yaitu sebagai lambang produk kuliner. Penentuan posisi serta letak perlu dipertimbangkan. Dimana matahari menandakan kehangat dari Cafe rumah bako, gonjong rumah adat yang dibuat seperti
Gorga : Jurnal Seni Rupa

Volume 10 Nomor 02 Juli-Desember 2021

p-ISSN: 2301-5942 | e-ISSN: 2580-2380

daun menandakan letak Cafe tersebut di payakumbuh yang kuat adat minangnya, cangkir dan garis tegas itu menandakan di Cafe tersebut bisa untuk berbicara santai sambil minum dan makan, simbol garpu dan sendok adalah tempat makan atau Resto ran, icon musik yang menandakan di Cafe tersebut melakukan band atau musik untuk menghibur pengunjung dan bisa juga pengunjung untuk bernyanyi, sedangkan simbol daun menandakan banyaknya pepohonan dan tempat yang asri sekitaran Cafe tersebut.

\section{Saran}

Berkaitan dengan tampilan ruang, ada beberapa hal yang disarankan oleh penulis guna meningkatkan kenyamanan customer yaitu dalam kondisi yang ramai, Cafe dan Resto rumah bako Payakumbuh sering mengalami perubahan formasi tempat duduk dan terkadang pada saat pengembaliannya kurang sesuai seperti di awal oleh sebab itu sebaiknya desainer perlu menciptakan desain pengaturan elemen pengisi ruang, seperti meja dan kursi. Selain itu pihak Cafe dan Resto Rumah Bako Payakumbuh untuk terus menjaga kualitas dan berinovasi agar bisa bersaing dengan usaha bidang kuliner dengan menu masakan antara perpaduan minang dan modern. Sehingga hal itu akan bisa menjadi daya tarik kepada masyarakat. Sosialisasi desain ini bisa lebih baik jika di sampai pada Direktorat Jenderal Hak kelayakan intelektual (Dirjen HAKI) pengenalan masyarakat, berupa logo yang terpasang di cafe terkait.

\section{DAFTAR RUJUKAN}

Anggakarti, D. M., \& Benyamin, M. F. (2021). Adaptasi Gambar Hias sebagai Gambar Latar pada Aplikasi Desain. Journal VISUALIDEAS, 1(1), 3-7.

Arbi, M. S., Irwan, M. S., \& Hafiz, A. (2019). Ayam Jantan Dalam Karya Seni Grafis. Serupa The Journal of Art Education, 7(3).

Arredondo, E., Castaneda, D., Elder, J. P., Slymen, D., \& Dozier, D. (2009). Brand name logo recognition of fast food and healthy food among children. Journal of Community Health. https://doi.org/10.1007/s10900-008-9119-3

Atika, J. (2019). Kajian Interior Ruang Tidur pada Anak. PROPORSI: Jurnal Desain, Multimedia Dan Industri Kreatif, 1(1), 28-38.

Fadilah, A., Mappalahere, M. T., \& Mukaddas, A. B. (2021). Kajian Estetika Sangkar Burung Puyuh (Jaba Kawubu) di Kampung Rupe Kecamatan Langgudu Nusa Tenggara Barat. BALOLIPA: Jurnal Pendidikan Seni Rupa, 1(1), 43-50.

Jaya, M. A. (2018). Transformasi Tempat Ketiga (Third pl\#ace) dari Ruang Dalam (indoor) 
Menuju Ruang Luar (Outdoor): Studi Kasus Kota Palembang. https://doi.org/10.32502/arsir.v2i1.1240

Jia, Y., Shelhamer, E., Donahue, J., Karayev, S., Long, J., Girshick, R., Guadarrama, S., \& Darrell, T. (2014). Caffe: Convolutional Architecture for Fast Feature Embedding. MM 2014 . Proceedings of the 2014 ACM Conference on Multimedia.

https://doi.org/10.1145/2647868.2654889

Lee, C., Hallak, R., \& Sardeshmukh, S. R. (2016). Innovation, entrepreneurship, and restaurant performance: A Higher-Order Structural Model. Tourism Management. https://doi.org/10.1016/j.tourman.2015.09.017

Luffarelli, J., Mukesh, M., \& Mahmood, A. (2019). Let the Logo Do the Talking: The Influence of Logo Descriptiveness on Brand Equity. Journal of Marketing https://doi.org/10.1177/0022243719845000

Mubarat, H., \& Ilhaq, M. (2021). Telaah Nirmana sebagai Proses Kreatif Dalam Dinamika Estetika Visual. Ekspresi Seni: Jurnal Ilmu Pengetahuan Dan Karya Seni, 23(1), 125-139.

Mulyawartini, G. A. (2019). Melalui Kegiatan Meronce Bentuk Dan Warna Dapat Meningkatkan Kemampuan Motorik Halus Anak Pada Kelompok B Tk Harapan Kelayu. Jurnal EDISI, l(1), 118-133.

Munawaroh, S. D. (2018). Pengaruh Media Bola Warna terhadap Kemampuan Mengenal Warna Anak Kelompok A di TK Dahlia Jagir Sidoresmo Surabaya. Jurnal PAUD Teratai, 7(1).

Putri, S. M., \& Hartati, M. (2021). Pakaian Tradisional Perempuan Melayu Jambi. Seminar Nasional Humaniora, 1(1), 116-133.

Said, A. A. (2019). Mendesain Logo. TANRA: Jurnal Desain Komunikasi Visual Fakultas Seni Dan Desain Universitas Negeri Makassar. https://doi.org/10.26858/tanra.v6i3.13014

Sakriyani, A. (2018). Pembuatan Company Profil Politeknik NSC Surabaya Menggunakan Adobe After Effects CC 2014. Politeknik NSC Surabaya.

Susilawati, H., Akhmad Fauzi Ikhsan, M. T., \& Salman, F. (2020). Prototyping Alat Pendeteksi Kematangan Buah Kopi Berbasis Arduino Menggunakan Sensor Apds Gy-9960. Jurnal Penelitian Dan Pengembangan Teknik Elektro Telekomunikasi Indonesia, 11(1).

Van Der Vorst, J. G. A. J., \& Beulens, A. J. M. (2002). Identifying Sources of Uncertainty to Generate Supply Chain Redesign Strategies. International Journal of Physical Distribution \& Logistics Management.

https://doi.org/10.1108/09600030210437951
Gorga : Jurnal Seni Rupa

Volume 10 Nomor 02 Juli-Desember 2021

p-ISSN: 2301-5942 | e-ISSN: 2580-2380

Wagner, M., Rietz, C., Kaspar, R., Janhsen, A., Geithner, L., Neise, M., Kinne-Wall, C., Woopen, C., \& Zank, S. (2018). Quality of life of the Very Old. Zeitschrift Für Gerontologie Und Geriatrie, 51(2), 193-199.

Wangarry, M. A., \& Saidi, A. I. (2018). Pengaruh iklan Media Luar Ruang pada Ruang Publik di Kota Jakarta Selatan. Jurnal Seni \& Reka Rancang. 